\title{
Acknowledgment of Reviewers
}

Published online: 23 May 2015

(C) Springer International Publishing Switzerland 2015

Please join us in thanking all those scientists and experts in the various fields represented in Computational Geosciences, for devoting their time and effort to review the papers that we have been sending them. The editors and publisher acknowledge these colleagues for their excellent reviews of papers for which final decisions have been made in 2014. 